\title{
A SURVEY ON OPTIMIZATION BASED SPECTRUM SENSING TECHNIQUES TO REDUCE ISI AND PAPR IN OFDM BASED COGNITIVE RADIO SYSTEM
}

\author{
${ }^{1}$ Mr.B.Maheswara Rao, ${ }^{2}$ Dr.S.Baskar \\ ${ }^{1}$ Research scholar, ${ }^{2}$ Professor, Department of EEE, \\ Vel Tech Rangarajan Dr. Sagunthala R\&D Institute of Science and Technology \\ maheswar414@gmail.com, drbaskar@veltechuniv.edu.in,
}

\begin{abstract}
Cognitive radio is emerging technologies in OFDM based wireless systems which are very important for spectrum sensing. By using cognitive radio (CR) high data can be transferred with low bit error rate. The key idea of OFDM is to split the total transmission bandwidth into the subcarriers which further reduce the intersymbol interference (ISI) and peak to average power ratio(PAPR) in the signal. There are many optimization based spectrum sensing techniques are existing for efficient sensing purpose but each has its own advantages and disadvantages. This leads to start the comprehensive study for reducing PAPR and ISI(Intersymbol interference) in terms of FPGA based partial configuration. In the first part of review OFDM characteristics of the signal has compared with several optimizations based ISI reduction techniques. The second part is to compare the various spectrum sensing techniques in cognitive radio engine and its application in FPGA.
\end{abstract}

\section{KEYWORDS \\ Cognitive radio, Inter symbol interference (ISI), Spectrum sensing, OFDM}

\section{INTRODUCTION}

As the wireless devices and applications are increasing, the available electromagnetic spectrum becomes increasingly crowded due to limitations of spectrum access. Hence, many studies and researches have been done in order to utilize the available spectrum efficiently. Therefore, the concept of opportunistic usage of frequency bands using cognitive radio is introduced. Cognitive radio is defined as a radio that senses its electromagnetic environment and changes its transmission or reception parameters dynamically and autonomously [1]. Furthermore, cognitive radio allows unlicensed users to access licensed frequency bands through dynamic spectrum access. One of the main function of cognitive radio is spectrum sensing. The most popular spectrum sensing techniques are classified into two categories: Non-Cooperative and Cooperative sensing. In non-cooperative sensing, the detection of a Primary User (PU) signal is based on the received signal at a cognitive radio user, such as energy detection [2], matched filter detection and cyclo stationary feature detection [3], each of these techniques has its strengths and weaknesses. In a conventional parallel data system, the total signal bandwidth can be divided into $\mathrm{N}$ nonoverlapping frequency sub-channels. Each sub-channel is modulated with a separate symbol and then the $\mathrm{N}$ subchannels are frequency multiplexed. To eliminate the inter-carrier interference (ICI), a spectral overlap is avoided i.e. empty spectral region is provided, between two adjacent sub-channels. But this results in inadequate use of the ready spectrum [4]. The concept was recommended in the mid-1960s, to handle with this wastefulness, through the advancement of frequency division multiplexing (FDM) with overlapping sub-channels. The sub-channels were 
International Journal of Network Security \& Its Applications (IJNSA) Vol. 11, No.1, January 2019 ordered so that, the sidebands of the individual carriers overlap without inducing ICI. To accomplish this, the carriers must be mathematically orthogonal.

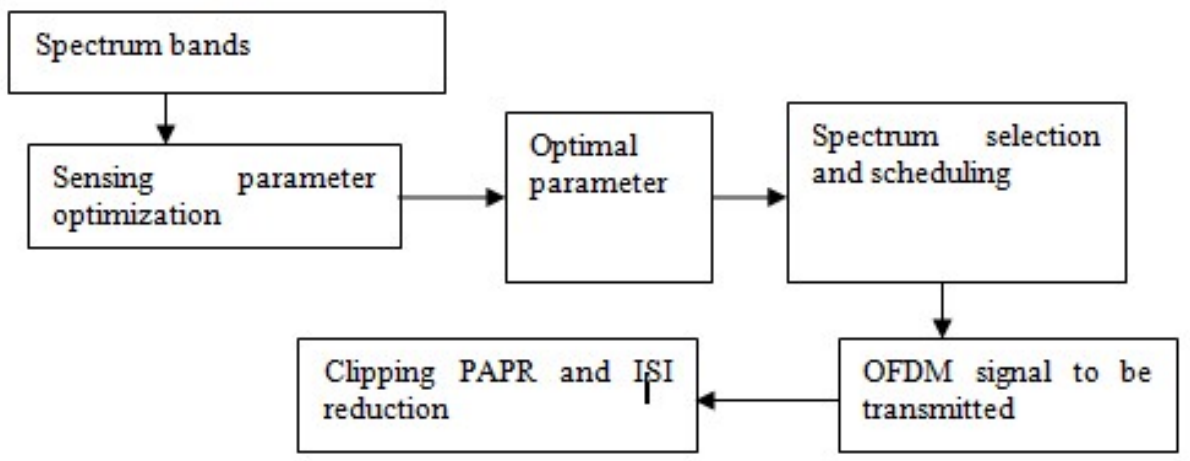

Figure-1 Block diagram of sensing the bands and to reduce ISI

It is proficient advanced transmission procedure for fourth Generation correspondence. OFDM is multicarrier in nature which utilizes the number of subcarriers for multiplexing. These subbearers are orthogonal and are covered with each other. OFDM is better to answer for fast advanced correspondence. One of the real disadvantages of the OFDM signals is Peak to Average Power Ratio (PAPR) [5]. The most extreme pinnacle of the transmitted flag happened when numbers of signs of the same stage are included intelligibly.

With a high measure of PAPR, the power intensifiers work in a non-straight district so it requires expansive power back-off [6], which makes the framework much costly. In the event that a power intensifier does not work in direct locale, it is hard to keep out of band radiation underneath a particular farthest point. This sort of approach includes Selective Mapping (SLM) [7] and Partial Transmit Sequences (PTS). SLM strategy applies scrambling turn to all sub-transporters autonomously while the PTS technique just takes scrambling to some portion of the sub-bearers.

\section{Optimization BASEd Isi ANd PAPR Reduction TeChNiQues}

Kuldeep Singh et al.,[8] proposed a PTS in light of Cuckoo Search (CS) Algorithm (CS-PTS) has been proposed for a proficient diminishment of PAPR with fewer ventures keeping in mind the end goal to beat the drawback of the regular PTS. The unmistakable drawbacks of further expanding the number of sub-pieces are that the time postponement and many-sided quality of framework increments. It depends on look methodology of a cuckoo feathered creature and it recreates the forceful regenerative technique of the winged creature. Reenactment result demonstrates that the CS-PTS stage streamlining plan can accomplish better PAPR lessening.

Huynh et al.,[9] adjusted a manufactured honey bee province (ABC) calculation, which is an approach in light of arrangement sets to tackle combinatorial and numerical improvement issues at the underlying advance, stage factor enhancements remember a worldwide ideal stage vector with the best wellness from the haphazardly delivered stage vectors.

Y. Wang et al..,[10] has thought about computational many-sided quality among the ABC-PTS and the current PAPR lessening techniques, for example, molecule swarm advancement calculation based PTS (PSO-PTS), the iterative flipping calculation for PTS (IPTS), slope plunge seek (GD), and the least separation guided hereditary calculation (MDGA). It is demonstrated that contrasted with the leaving PAPR diminishment strategies, the ABCPTS calculation has the most 
International Journal of Network Security \& Its Applications (IJNSA) Vol. 11, No.1, January 2019

reduced scan many-sided quality for bigger PTS sub-obstructs in the meantime and can show signs of improvement PAPR lessening execution.

Tellado et al., [11] proposed the TR strategy in light of flag to cut-out commotion control proportion to decrease the many-sided quality of the minimization methodology. The remedial flag is evaluated by means of these four enhancement solvers, in particular, Gradient calculation, Fletcher-Reeves and Polak-Ribiere Conjugate-Gradient and Quasi-Newton strategies. Reproduction comes about on the IEEE 802.11a standard demonstrate that conjugate slope solver gives better execution in term of PAPR lessening addition and merging pace contrasted with Quasi-Newton and Gradient calculations.

Eakhwan Song et al.,[12] proposed an advancement technique in light of a logical estimation strategy for educational and jitter was presented. In spite of the fact that the strategy shows a quantitative improvement approach, it is less appropriate for complex tuning of the outline parameters because of the suspicion that voltage-time bend has a perfect direct slant in the diagnostic estimation. the proposed strategy has been effectively approved with a huge change in both recurrence and time spaces

\section{Spectrum Sensing TechniqueS}

Bahi et al.,[13] proposed another location plan of OFDM PUs signals utilizing Singular Value Decomposition (SVD) of Second-Order Statistics (SOS) of the got signals at the Secondary Users (SUs), so as to choose the nearness/nonattendance of OFDM PUs signals. The decision of OFDM tweak is because of the way that it is all the more broadly utilized as a part of remote interchanges (e.g. 3GPP/LTE (third Generation Partnership Project/Long Term Evolution) for the downlink, WiFi, WiMAX (Worldwide Interoperability for Microwave Access), DVBT (Digital Video Broadcast Terrestrial)), in light of its high transmission capacity productivity.

Ming Liu et al., [14] proposed an accepted spectrum sensing techniques for TDS-OFDM are focused around the misuse of the PN grouping and therefore experience the ill effects of inter symbol impedance (ISI). This paper proposes a novel information supported channel estimation system which joins the channel assessments acquired from the PN arrangement and, above all, extra channel evaluations separated from OFDM information images. Information helped channel estimation is completed utilizing the reconstructed OFDM information images as virtual preparing successions.

Cognitive radio (CR) cannot sense the presence of primary user, and thus it allowed accessing the channel while the PU is still in operation. To address this issue or to overcome this problem multiple CRs can be considered to collaborate in spectrum sensing. Khaled Ben Letaif et al.., found that in cooperative spectrum sensing, all CRs identify the availability of licensed spectrum individually. Each cooperative partner makes a binary decision based on its local observation and forward one bit of the decision to the common receiver. As a result OFDM has great advantage over fading channel so OFDM is very robust against the inter symbol interference (1SI). So we get higher probability of detection for low Probability of false alarm[15].

In [16], Zhang and Leung proposed a low complexity suboptimal algorithm for an OFDM-based CR system in which SUs may access both non active and active PU frequency bands, as long as the total CCI and ACI are within acceptable limits.

Bansal et al. [17] investigated the optimal power allocation problem in CR networks to maximize the SU downlink transmission capacity under a constraint on the instantaneous interference to 
International Journal of Network Security \& Its Applications (IJNSA) Vol. 11, No.1, January 2019

PUs. The proposed algorithm was complex and several suboptimal algorithms were developed to reduce the computational complexity.

\section{OFDM WITH FPGA}

S. Haene, D. Perels and A Burg [18] recommended that A constant MIMO-OFDM physical layer transmitting at a pinnacle information rate of $216 \mathrm{Mbit} / \mathrm{s}$ more than $20 \mathrm{MHz}$ transfer speed was prototyped and described through estimations. Constant operation of the framework on a FPGA was accomplished by steady choice and enhancement of the utilized handset calculations for the FPGA usage and via cautious plan of the comparing handset equipment design.

Arun Kumar K An et al.,[19] portrays in the headway of present-day time remote correspondence frameworks, reconfigurable innovation plays a basic obligation. The Baseband FPGA execution of an OFDM transmitter is likewise talked about in this paper. The module is executed utilizing a strategy called fractional reconfiguration with the goal that somebody can swap between unmistakable tweak strategies, coding systems and number sub-bearers requested in less time. In this PR based execution of OFDM Transmitter, a more prominent region of the Modulator, coding and IFFT modules will be static and a lesser zone will be dynamic. At the season of swapping just the dynamic zone of the FPGA is reconfigured in less time which will diminish power and setup time.

Veena and Swamy[20] performed the examination of DWT based OFDM over FFT construct OFDM and actualizing in light of FPGA propose a DWT-IDWT based OFDM transmitter and recipient that accomplish better execution in wording SNR and BER for AWGN channel. It demonstrates all the wavelet families better finished the IFFT-FFT usage. The OFDM display is produced utilizing Simulink, different experiments have been considered to confirm its execution.

\section{FINDINGS:}

1. It is powerless against the impacts of frequency offset. OFDM sub-bearer ranges cover one another, which require strict symmetry among them. Frequency offset impedes symmetry and can likewise debase demodulation execution. Time balance can prompt OFDM image impedance and adequacy weakening.

2. The utilization of OFDM presents a high pinnacle normal power proportion. It is realized that in OFDM, the yield is a superposition of sub-transporters. At the point when the periods of transporters are the equivalent, this could prompt some quick power yields which are higher than the mean intensity of the framework. This outcomes in a bigger Peak-to-Average Power Ratio (PAPR). At the point when the pinnacle control is excessively high, it could be out of scope of straight power speakers. This offers ascend to non-straight mutilation and changes the superposition of the flag range. It additionally devastates sub-transporter symmetry and debases the execution of OFDM.

3. On a very basic level OFDM is a multicarrier transmission system wherein a single higher rate data transporter is isolated into a considerable number of parallel lower rate data bearers which are solely called as sub-transporters, hence decreasing the Inter picture Interference (1SI) in light of gigantic picture length not in any manner like the standard Frequency Division Multiplexing (FDM) advancement. 
International Journal of Network Security \& Its Applications (IJNSA) Vol. 11, No.1, January 2019

\section{COMPARATIVE EXAMINATION}

In this segment different existing Optimization based ISI diminishment strategies are thought about as far as time delay, The FPGA based arrangement methods is analyzed regarding setup time, dormancy, control which have confinements and favourable circumstances in different parameters.

Table 1. Comparison Of Optimization Based Isi And Paper Reduction Techniques

\begin{tabular}{|l|l|l|l|l|l|l|}
\hline Techniques & PAPR & Time delay & $\begin{array}{l}\text { Power } \\
\text { consumption }\end{array}$ & SNR & BER & $\begin{array}{l}\text { Convergence } \\
\text { rate }\end{array}$ \\
\hline $\begin{array}{l}\text { Cuckoo Search } \\
\text { (CS) } \\
\begin{array}{l}\text { Algorithm } \\
\text { (CS-PTS) }\end{array}\end{array}$ & $\begin{array}{l}\text { Better } \\
\text { reduction }\end{array}$ & less & more & more & moderate & Moderate \\
\hline $\begin{array}{l}\text { An artificial } \\
\text { bee colony } \\
\text { (ABC) } \\
\text { algorithm }\end{array}$ & $\begin{array}{l}\text { Considerable } \\
\text { amount of } \\
\text { reduction }\end{array}$ & More & moderate & less & More & Moderate \\
\hline $\begin{array}{l}\text { ABC-PTS } \\
\text { BBtter } \\
\text { reduction }\end{array}$ & $\begin{array}{l}\text { Less } \\
\text { reduction } \\
\text { estimation } \\
\text { method eye } \\
\text { opening with } \\
\text { optimization }\end{array}$ & Moderate & Less & Moderate & More & Very less \\
\hline $\begin{array}{l}\text { Singular Value } \\
\text { Decomposition } \\
\text { (SVD) }\end{array}$ & $\begin{array}{l}\text { Moderate } \\
\text { reduction }\end{array}$ & Less & Moderate & Less & More & More \\
\hline $\begin{array}{l}\text { TDS-OFDM } \\
\text { reduction }\end{array}$ & $\begin{array}{l}\text { Less } \\
\text { more }\end{array}$ & more & Less & Moderate & Moderate \\
\hline
\end{tabular}

Table-2 Comparison Of Fpga Configuration Techniques

\begin{tabular}{|c|c|c|c|c|}
\hline Methods & Configuration time & Latency & Power & Memory \\
\hline $\begin{array}{c}\text { FPGA } \\
\text { prototyped } \\
\text { OFDM }\end{array}$ & more & more & Less & \\
\hline $\begin{array}{c}\text { Cordic based } \\
\text { Partially } \\
\text { Reconfigurable } \\
\text { FPGA Module }\end{array}$ & Very less & moderate & very less & Less \\
\hline $\begin{array}{c}\text { DWT -FPGA } \\
\text { based OFDM }\end{array}$ & & & & \\
\hline
\end{tabular}

\section{Conclusion}

In this paper, an overview of different strategies for advancement based ISI lessening systems, range detecting methods and FPGA arrangement procedures are inspected as far as a postponement, normal power, SNR and BER. It is extremely surely known that all strategies function admirably for various purposes. The points of interest and hindrances of these strategies are talked about. There are sure issues recognized, for example, FPGA incomplete reconfiguration, however, experiences the ill effects of poor transmission capacity distribution, which prompts wasteful information exchange systems with expanded power utilization and 
International Journal of Network Security \& Its Applications (IJNSA) Vol. 11, No.1, January 2019

diminished throughput. Latencies can't be accomplished utilizing a product baseband running over a working framework or even continuous working framework.

\section{REFERENCES}

[1] Q. Zhao and B. M. Sadler, "A survey of dynamic spectrum access," Signal Processing Magazine, IEEE, vol. 24, no. 3, pp. 79-89, 2007.

[2] A. Taherpour, M. Nasiri-Kenari, and S. Gazor, "Multiple antenna spectrum sensing in cognitive radios," IEEE Transactions on Wireless Communications, vol. 9, no. 2, pp. 814-823, 2010

[3] W. A. Gardner, A. Napolitano, and L. Paura, "Cyclostationarity: Half a century of research," Signal processing, vol. 86, no. 4, pp. 639-697, 2006

[4] Anurag Tiwari, SanketPhapal, DhirajKadam, Sivanantham S, Sivasankaran K, "FPGA Implementation of FFT Blocks for OFDM", IEEEOnline International Conference on Green Engineering and Technologies,pp.978-982, 2015.

[5] Nilesh Chide, ShreyasDeshmukh, Prof.P.B.Borole, "Implementation of OFDM System using IFFT and FFT", International Journal of Engineering Research and Applications (IJERA), Vol.3, pp.20092013,2013

[6] W. Yajun, W. Chen and C. Tellambura, (2010), "A PAPR reduction method based on artificial bee colony algorithm for OFDM signals," IEEE Transactions on Wireless Communications, vol. 9, no. 10,pp. 2994-2999

[7] A. Gangwar and M. Bhardwaj, (2012), "An Overview: Peak to Average Power Ratio in OFDM system \& its Effect," International Journal of Communication and Computer Technologies, vol. 01, no. 02 , pp. $22-25$

[8] Kuldeep Singh, Balraj Singh Sidhu," PAPR Reduction of OFDM Signals Using Cuckoo Search Algorithm", International Journal of Computing and Technology, Volume 2, Issue 2, February 2015.

[9] Huynh hVo Trung Dung, Hakjeon Bang and Seungil Myong," PAPR Reduction using PTS with Low Computational Complexity in Coherent Optical OFDM Systems” IEEE Trans. Broadcast., vol. 53, no. 3, pp. 719-724, Sep. 2007

[10] Y. Wang, W. Chen, and C. Tellambura, "A PAPR Reduction Method Based on Artificial Bee Colony Algorithm for OFDM Signals,” IEEE Trans. Wirel. Commun., vol. 9, no. 10, pp. 2994-2999, Oct. 2010

[11] J. Tellado and J. M. Cioffi, "Peak power reduction for multicarrier transmission," in Proc. IEEE GLOBECOM. Conf, 2011

[12] Eakhwan Song, Juyeop Kim, Jiseong Kim,” A Passive Equalizer Optimization Method Based on Time-Domain Inter-Symbol Interference (ISI) Cancellation Technique" IEEE TRANSACTIONS ON ELECTROMAGNETIC COMPATIBILITY, 2017 IEEE

[13] F. Z. El Bahi, H. Ghennioui, M. Zouak," Spectrum Sensing Technique for Cognitive Radio of Multiple OFDM Signals based on Singular Value Decomposition" 2016, IEEE transactions on communications, vol. 57, no. 6, pp. 1784-1793 
International Journal of Network Security \& Its Applications (IJNSA) Vol. 11, No.1, January 2019

[14] Ming Liu, Matthieu Crussière, and Jean-François Hélard, “A Novel Data-Aided Channel Estimation with Reduced Complexity for TDSOFDM Systems” IEEE Transactions on Broadcasting, VOL. 58, NO. 2, JUNE 2012247

[15] Khaled Ben Letaife, Fellow IEEE and Wei Zhang, "Cooperative communications for Cognitive Radio Networks", proceeding of IEEE, vol-97 No-5 May 2009.

[16] Y. Zhang and C. Leung, "An efficient power-loading scheme for OFDMbased cognitive radio systems,” IEEE Trans. Veh. Technol., vol. 59, no. 4, pp. 1858-1864, May 2010

[17] G. Bansal, M. Hossain, and V. Bhargava, "Optimal and suboptimal power allocation schemes for OFDM-based cognitive radio systems,” IEEE Trans. Wireless Commun., vol. 7, no. 11, pp. 4710 4718, Nov. 2008.

[18] M.A. Mohamed1, A.S. Samarah1, M.I. Fath Allah2, "A Novel implementation of OFDM using FPGA", IJCSNS International Journal of Computer Science and Network Security, VOL.11 No.11, November 2011

[19] Arun Kumar K A, "An OFDM Transmitter Implementation using Cordic based Partially Reconfigurable IFFT Module", IEEE3rd International Conference on Eco-friendly Computing and Communication Systems, pp.266-270,2014.

[20] Mrs. VEENA M.B1 \& Dr. M.N.SHANMUKHA SWAMY," Performance analysis of DWT based OFDM over FFT based OFDM and implementing on FPGA" International Journal of VLSI design \& Communication Systems (VLSICS) Vol.2, No.3, September 2011.

\begin{abstract}
AUTHOR
Mr.B.MaheswaraRao received his B.Tech in (Electronics \& Communication Engineering) from - Sri Raja Rajeswari Engineering College (JNTUH) in 2006 and M.Tech (VLSI System Design)-From Hyderabad Institute of Technology \& Management (JNTUH) in 2010 and Advanced Diploma in Data Science and Big Data Analytics from National Institute of Electronics and Information Technology, Calicut, in March-July 2017, Student Member of IEEE, respectively. Currently, working towards the Ph.D. degree in Electronics and Communication Engineering, from Veltech Rangarajan Dr.Sagunthala R\&D Institute of Science and Technology, Avadi, Chennai India. His research interests include VLSI Technology \& Design, Wireless Communication and Networks, MIMO-OFDM, Cognitive Radio Networks.

Dr.S.Baskar received his B.E (Electrical \& Electronics Engineeering) from Annamalai University and M.Tech (Power Electronics) from Vellore Institute of Technology, India. He has completed his Ph.D - EEE in the specialization area of FACTS controllers from Annamalai University. $\mathrm{He}$ is currently working as Professor in the Department of Electrical and Electronics Engineering, at Veltech Rangarajan Dr.Sagunthala R\&D Institute of Science and Technology, Avadi, Chennai, India. His research interests include Power Electronics, Control and Modeling of FACTS Controllers and its application to power system
\end{abstract}
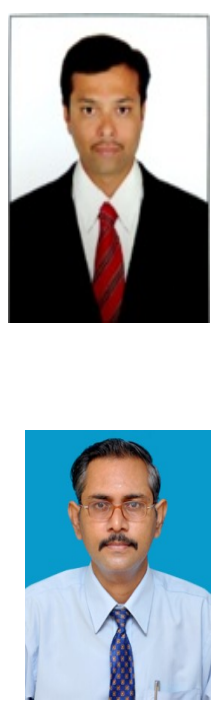